\title{
INTEGRATED MULTI-CRITERIA PLANNING MODEL OF THE USE OF HYDROELECTRICITY SURPLUS OF PARAGUAY BASED ON ANALYTIC NETWORK PROCESS (ANP)
}

\begin{abstract}
The abundance of electric energy, generated mainly by the binational hydroelectric dams of Itaipú and Yacyretá, constitutes a strategic asset for the development of Paraguay. This has a great impact on the economic growth and social progress of the country, through the planned infrastructure growth and the development of the productive sector, mainly industry, based on a greater share of electricity in the energy matrix. In fact, it can be said that Paraguay, from different perspectives, urgently needs to take advantage of the large levels of clean energy available, encouraging the penetration of hydropower into the energy demand matrix, replacing biomass and oil.

In this context, a wide public debate on the use of hydropower surplus has been around in the country for many years. The different alternatives for its implementation are often characterized by the conflict between different objectives, such as political, social, economic, technical and environmental points of view. With this proposal, it is planned to generalize the analysis hierarchical process, the Analytic Network Process (ANP) to develop a decision-making tool for the best use of Paraguay's hydroelectric surpluses within the framework of a sustainable policy, considering quantitative and qualitative aspects, difficult to identify through usual evaluation approaches. This tool has a high scientific and avant-garde component to make essential decisions that would produce the greatest benefits for the integral development of the country.
\end{abstract}

Keywords: ANP, Electric Energy, Energy Policy

\section{Introduction}

The abundance of electric energy, generated mainly by the binational hydroelectric dams of Itaipú and Yacyretá, constitutes a strategic asset for Paraguay's development which generates a great impact on the economic growth and social progress of the country, through planned infrastructure growth and development of the productive sector, mainly industry, based on a greater share of electricity in the energy matrix.

However, within the country's energy matrix, there is still a significant share of biomass, oil-based energy sources and limited electricity penetration. In fact, it can be said that Paraguay, from different perspectives, urgently needs to take advantage of the high levels of clean energy available, encouraging the penetration of hydropower into the energy demand matrix, replacing biomass and oil.

In this context there has been, for many years, a wide public debate on the use of hydropower surplus. The different alternatives for its implementation are often characterized by the conflict between different objectives, such as political, social, economic, technical and environmental points of view. Due to the complexity of the negotiations among different agents involved, a unique idea about the best alternative is difficult to reach. However, the general perception of Paraguayan society is unified in the sense that policymakers must make decisions that provide the greatest benefits to the country.

This proposal promotes the use of the Analytic Network Process (ANP), which is a generalization of the AHP, in order to provide a decision-making tool regarding the use of 
Paraguay's hydroelectric surpluses within the framework of a sustainable policy, considering quantitative and qualitative variables that are generally difficult to consider through usual evaluation approaches.

\section{Literature Review}

\subsection{Paraguay's Energy Outlook: Background and Issues}

Paraguay has very particular characteristics regarding energy. It is possible to highlight the large hydroelectric power production capacity, as it has three large power plants: Itaipú (Paraguay-Brazil), with an installed capacity of $14,000 \mathrm{MW}$, of which $50 \%$ belongs to Paraguay, and the remaining 50\% belongs to Brazil; Yacyretá (Paraguay - Argentina), with an installed capacity of $3200 \mathrm{MW}$, of which 1,600 MW belongs to Paraguay and the other half to Argentina, and Acaray - exclusive property of Paraguay - with an installed capacity of $210 \mathrm{MW}$.

According to data from the National Energy Balance of 2014, primary energy production is distributed in hydroelectricity with $67 \%$ and biomass with $33 \%$. Of this $67 \%$ of hydropower produced, $80.7 \%$ is exported to Brazil and Argentina.

Electricity accounts for only $17.9 \%$ of final energy consumption, which represents a paradox, since there is a large production of clean and renewable electricity but a low consumption of electricity. The remaining configuration in terms of final energy consumption is complemented by oil derivatives by $37.7 \%$ and biomass by $44.4 \%$.

Itaipú Binacional is the main source of electricity in Paraguay. This plant was conceived from a binational treaty, which was signed in 1976 between Paraguay and Brazil for the development and exploitation of the hydroelectric potential of the Paraná River. Itaipú produces about 90,000 GWh / year Given that Paraguay consumes only about $10 \%$ of its total quota, unused electric energy is transferred to Brazil in exchange for an economic compensation established in the 1976 treaty, which stipulates that the surplus not consumed by one of the parties, will be transferred to the other contracting party, restricting the possibility of selling the energy to third parties. Although Paraguay is the largest net exporter of hydroelectric power in the world, almost half of its domestic energy consumption is made up of biomass, so the country has one of the highest deforestation rates in the world.

Given this scenario, the main problem is that Paraguay does not maximize the surplus electricity available, so there is currently a significant share of unsustainable biomass and oil-based energy sources that represent a clear imbalance in the country's energy security, the environment and the quality of life of the population.

Taking into account the large surplus of clean and renewable electric energy, it can be said that Paraguay, from different perspectives, needs to take advantage of the large levels of clean electric energy available, encouraging the penetration of hydropower into the energy demand matrix, Replacing biomass and oil.

\section{Hypotheses/Objectives}

Propose a model based on the Analytical Network Process (ANP) to develop a decisionmaking tool in relation to the best use of Paraguay's hydroelectric surplus within the framework of a sustainable policy for achieve a social welfare and development.

\section{Analytic Network Process}

The Analytic Network Process (ANP) is a decision-making method proposed by Saaty (2013), Saaty et al. (2013), which generalizes a widely used multi-criteria decision-making tool, the AHP (Analytic Hierarchy Process), replacing hierarchies by networks. 
AHP is a well-known technique that breaks down a problem at several levels in such a way that they form a hierarchy. But many decision problems cannot be structured hierarchically because they involve the interaction and dependence of higher-level elements on a hierarchy in lower-level elements. Therefore, the ANP is represented by a network, rather than a hierarchy.

The feedback structure of the ANP, as mentioned recently, does not have the form of a hierarchy (top to bottom) but of a network, with cycles connecting the elements (The elements are composed of nodes which in turn can be grouped into Clusters), so they can no longer be called levels, and with loops that can connect a component to itself.

It also has sources and sinks. A source node is an origin of paths of influence (importance) and never a destination of such paths. A sink node is a destination of paths of influence and never an origin of such paths.

A complete network may include source nodes; intermediate nodes that fall on routes from source nodes, are in cycles, or fall on the paths of the sink nodes; and finally sink nodes. Some networks can only contain source and sink nodes. Still others may include only source and cycle nodes or cycle and sink nodes or only cycle nodes. A decision-making problem with feedback often arises in practice, in real life, and can take the form of any of the networks just described.

\section{Data/Model Analysis: Evaluation of Alternatives for hydroelectric energy surpluses use in Paraguay based on an ANP model}

In this research the ANP methodology is used to structure the problem and measure (to improve metrics used by Blanco et al (2017), through the AHP for decision making) the analogical reasoning involved in making optimal decisions to use the surplus of hydroelectric power in Paraguay. A methodology that consists of two parts is applied. Firstly, the structuring of the problem in which the clusters, the elements and the relations between them are established, besides establishing the parameters and the data to make the comparisons according to the relations established. Secondly, calculations of the priorities of the elements (in this case, the alternatives) are carried out.

\subsection{Structuring the problem}

\subsubsection{Clusters, elements}

Clusters, in which the elements studied in this article are grouped, are detailed below.

Cluster 1- Objective (O): with the implementation of the ANP for this case study it is intended to answer the following question: What is most convenient for the country in terms of hydroelectric energy surplus in Paraguay?

Cluster 2 - Environmental Criterion (C1): The indicator for this criterion is the average growth rate of greenhouse gases emission, which is estimated by a projection that includes energy consumption as an exogenous variable. Time series analysis is performed based on historical data on $\mathrm{CO}_{2}$ emissions in Paraguay.

Cluster 3 - Economic Criterion (C2): The indicator for this criterion is the average annual growth rate of the country's GDP over the horizon analyzed. The projection of GDP is estimated by means of historical time series. Each alternative has a special treatment in terms of its marginal contribution to GDP.

Cluster 4 - Social Criterion (C3): The indicator for this criterion is the number of jobs that would be generated by each strategy. It is calculated by projections based on historical data or specific additional studies depending on the strategy being analyzed.

Cluster 5 - Technical Criterion (C4): The indicator for this criterion is the Expected Cost of Energy Not Supplied (ECENS). In this analysis, the electric demand growth rate is considered uncertain and its evolution is replicated through Monte Carlo simulations 
through a Brownian Movement (BM). In addition, contingency analyses of transmission lines are made in each iteration. Finally, Optimal Power Flows (OPF) are calculated in the power system of Paraguay in order to determine the minimum ECENS of each hour, iteration and contingency along the analysis horizon.

Cluster 6 - Feasibility Criterion (C5): it is established a classification based on the expert knowledge of an effective implementation probability of analyzed alternatives.

Cluster 7 - Alternatives (A): They are the different strategies assumed and analyzed in this case study. Its elements are:

A1 - Business as Usual "BAU": Paraguay remains ceding its electricity surplus to Brazil. A2 - High hydropower exportation level: Electricity is sold in the Brazilian wholesale power market at market prices of around 50USD/MWh.

A3 - High electro-intensive industry penetration level: a factory resembling Aluminum Smelter RTA of $1100 \mathrm{MW}$ is installed in the year 2017.

A4 - High development of small industry: Many small industries are installed. Industrial clusters of 180 MW are established beginning in 2017 and reach up an accumulated demand of $1100 \mathrm{MW}$.

Cluster 8 -Energy consumption E): This article proposes the consideration of consumption of electric energy having the following elements:

E1 - Total electric energy consumption in Paraguay: It is used with a factor of comparison between the clusters' elements, which are related to each other, having as indicator the total electricity consumption in Paraguay.

E2 - Total electric energy consumption of the industrial sector in Paraguay: Like the previous element, it is a factor that is used to compare other elements to each other, taking as an indicator the energy consumption of the industrial sector in Paraguay.

\subsection{Relations between clusters and network elements}

The relations or loops represent the different interactions among the clusters, which starts with the simple hierarchy objectives-criteria-Alternatives but with the variant of considering the factor of energy consumption with the criteria and also with the alternatives.

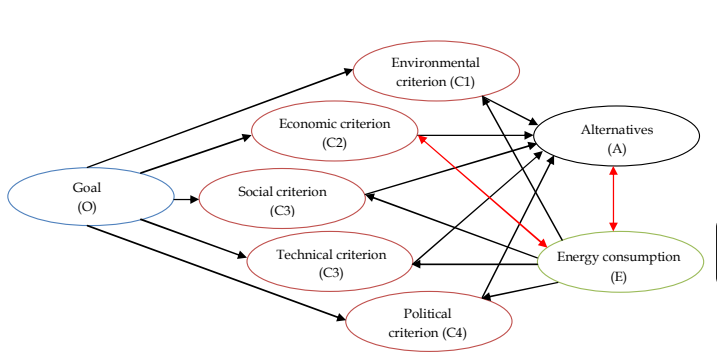

(a)

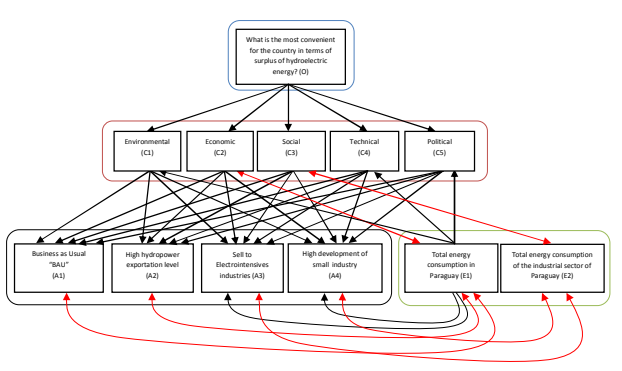

(b)

Figure 1: (a) Network structure of the relationships between clusters; (b) Network Structure of the ANP Model

\section{Limitations}

The use of electricity surplus in Paraguay has been one of the most recurrent public debates in recent years due to the conflicts between the objectives and the different alternatives regarding the use of this very important resource. This creates conflicts and difficulties for decision makers as there are multiple points of view.

Under these circumstances, this paper has proposed a multiple-criteria decision analysis approach (MCDA) to bridge the gap between multiple factors when making a decision. In particular, a model based on the Analytic Network Process (ANP) was used to develop a 
decision-making tool in relation to the use of Paraguay's hydroelectric surpluses in the framework of a sustainable policy.

This proposed model provides decision-makers with a scientifically rigorous tool, in which quantitative and qualitative aspects were considered, in addition to allowing the selection of the best strategy for the use of Paraguay's hydroelectric surplus.

\section{Conclusions}

The result of the use of the integral ANP model, taking into account the interaction between environmental, economic, social, technical and political criteria, as well as energy consumption in Paraguay (total and industrial sector) and possible strategies for this case study showed that the most convenient for Paraguay is to develop and implement the strategy A4 - High development of small industry with a $70.79 \%$ priority, presenting a greater superiority with respect to the other alternatives (A3 - High electro-intensive industry penetration (23.38\%), A1 - Business as Usual "BAU" (3.02\%) and A2 - High hydropower exportation level (2.81\%).

The results of the ANP model imply that the most appropriate strategy for Paraguay is the development of its industrial sector through the use of available electric energy, which would bring great benefits in many aspects compared to other alternatives.

\section{Key References}

Blanco, G., Amarilla, R., Martinez, A., Llamosas, C., \& Oxilia, V. (2017). Energy transitions and emerging economies: A multi-criteria analysis of policy options for hydropower surplus utilization in Paraguay. Energy Policy, 108, 312-321.

Saaty, T. L. (2013). Analytic network process. Encyclopedia of operations research and management science, 64-72.

Saaty, T. L., \& Vargas, L. G. (2013). Decision making with the analytic network process: economic, political, social and technological applications with benefits, opportunities, costs and risks (Vol. 195). Springer Science \& Business Media.

\section{Appendices}

The final result of the ANP model to determine the best strategy for the use of Paraguay's hydroelectric surplus is shown in Table 1:

\begin{tabular}{|c|c|c|c|c|}
\hline \multicolumn{1}{|c|}{ Table 1: General Outcome of the ANP Model } \\
\hline \multicolumn{1}{|c|}{ Cluster } & $\begin{array}{c}\text { Results of the limit } \\
\text { supermatrix }\end{array}$ & Normalization & $\begin{array}{c}\text { Priorities } \\
\text { (\%) }\end{array}$ \\
\hline \multirow{3}{*}{$\begin{array}{c}\text { A - } \\
\text { Alternatives }\end{array}$} & A1 - Business as Usual "BAU" & 0,0128 & 0,0302 & $3,02 \%$ \\
\cline { 2 - 5 } & A2 - High hydropower exportation level & 0,0119 & 0,0281 & $2,81 \%$ \\
\cline { 2 - 5 } & $\begin{array}{l}\text { A3 - High electro-intensive industry } \\
\text { penetration }\end{array}$ & 0,0994 & 0,2338 & $23,38 \%$ \\
\cline { 2 - 5 } & $\begin{array}{l}\text { A4 - High development of small } \\
\text { industry }\end{array}$ & 0,3008 & 0,7079 & $\mathbf{7 0 , 7 9 \%}$ \\
\hline \multicolumn{2}{|r|}{ Total } & $\mathbf{0 , 4 2 4 9}$ & $\mathbf{1}$ & $\mathbf{1 0 0 , 0 0 \%}$ \\
\hline
\end{tabular}

